\title{
Artificial Intelligence Disruption on Public Relations Practice: What do Practitioners Think About it
}

\author{
Doan Ilman Munandar ${ }^{1}$ and Irwansyah ${ }^{2}$ \\ doanilman@gmail.com ${ }^{1}$,dr.irwansyah.ma@gmail.com² \\ Department of Communication Science, University of Indonesia, Jakarta, Indonesia ${ }^{1,2}$
}

\begin{abstract}
Artificial Intelligence (AI) has become a prominence issue that will challenge the public relations industry in the era of the fourth industrial revolution or commonly called as the industry 4.0. AI is predicted to change the landscape of the public relations sphere because there is some concern that AI will take over the job of the public relations practitioners. This article discusses what public relations practitioners think about it. Study shows that although PR practitioners believe that AI could do some PR tasks at the low level, they have tendency to be sceptical about AI capabilities to accomplished a more complex of PR tasks that require certain types of intelligence.
\end{abstract}

Keywords: Public relations, artificial intelligence, industry 4.0, disruption

\section{Introduction}

The industrial revolution has a big impact on the field of human work. Since the invention of the steam engine in the industrial revolution 1.0, mass production machines in industry 2.0, computer and electronic automation in industry 3.0, and internet technology in industry 4.0, human work is increasingly helped by technology, or will even be increasingly replaced. Since the beginning of the birth of the industrial revolution in the 1700s and during the process of its development, technological improvement has reduced several types of jobs. In the 1900s, 41 percent of Americans worked in the agricultural sector; and in the 2000s the figure was only 2 percent. In the post-World War II period, 30 percent of Americans worked in the manufacturing sector, and now the remaining are 10 percent due to the growing development of automation, especially in the 1980s [1].

Along with the development of advanced technology in the industrial era 4.0 which included the emergence of Artificial Intelligence (AI) technology, there are many concerns that artificial intelligence technology will disrupt the work of humans in the future. This is because several studies related to artificial intelligence have begun to show significant results. For example, a car that can drive itself is predicted to eliminate the driver's job [2], or a greeting robot that can communicate that is predicted to replace the receptionist's job at the front office [3].

Researchers and expertise in the area of artificial intelligence predict that AI will exceed humans in many fields in the next ten years, such as translating languages (in 2024), completing high school level essays (in 2026), working in the retail industry (in 2031), wrote a best-seller book (in 2049), and act as a surgeon (in 2053) [2], although it is only a prediction 
based on their experience in the area of artificial intelligence research, therefore is supported by existing data. The researchers also predicted that in the next 45 years there is a 50 percent opportunity that artificial intelligence will exceed humans in all tasks, and in the next 120 years will automate all human work [2].

The communications industry such as public relations is also expected to be affected by the advancement of artificial intelligence technology. From a number of publications and news in Indonesia lately, it can be seen such discourse that there are opportunities for the use of artificial intelligence in public relations practices and challenges for public relations practitioners in the industrial era 4.0 [4][5][6][7]. Some of the headlines indicate anxiety including "Public Relations Profession Will Be Eroded by Artificial Intelligence" [6], "Dear PR Players, Ready to Face AI and Big Data Disruption?" [5], "Research Results, This PR Job Will Be Replaced by Machines" [4], and "Industrial Era 4.0 - What Are the Challenges of Public Relations in the Future?" [7].

There are many assumptions that the ability of artificial intelligence will equal or even exceed the ability of humans to do a job, as well as in carrying out public relations tasks, some estimates that someday artificial intelligence will be able to perform public relations tasks. This paper discuss how PR practitioners make sense of artificial intelligence disruption on public relations practice and should they be worried about it.

\section{Methodology}

Qualitative methods were used in this study. Both primary (interview) and secondary data (literature review) are collected. Telephone interviews were conducted with 5 PR practitioners who had more than three years of experience in public relations practice. Data were collected using semi-structured interviews. The interview guide was divided into two sections: (1) personal background, and (2) practitioners' thoughts toward utilization of AI on public relations practice. Interviews were recorded and transcribed.

To support the primary data collected from the interviews, secondary data needed. The data source used in this study is the latest scientific studies that have been previously studied such as scientific journals, articles and books that are relevant to the problems examined from the two literary streams related to artificial intelligence. There are two main research streams related to the advancement of artificial intelligence. The first literature is service and technology which tends to focus on the positive side of the use of artificial intelligence technology, and the second is economic that tends to focus on the effect of artificial intelligence on human work [8].

Table 1. List of Interview Participants

\begin{tabular}{cccc}
\hline Initial & Organization & Gender & $\begin{array}{c}\text { Experience as PR } \\
\text { Practitioner }\end{array}$ \\
\hline AN & Ministry of Finance & Female & 9 years \\
PW & Indonesian Institute of Sciences (LIPI) & Male & 10 years \\
RDM & Ministry of Trade & Male & 5 years \\
SS & Ministry of Science and Technology & Male & 3 years \\
PDP & The Audit Board (BPK RI) & Male & 4 years \\
\hline
\end{tabular}




\section{Literature}

\subsection{Public Relations}

Definition of Public Relations (PR) according to the Institute of Public Relations is "a planned and ongoing effort to build and maintain good faith and understanding between the organization and its public" [9]. Public relations is a management function that builds and maintains a good and beneficial relationship between the organization and the public that influences the success or failure of the organization. [10]. As a management function, practices in the public relations industry include the following [10]:

- Estimating, analyzing and interpreting opinions, public attitudes, and issues that might affect the organization's operations and plans;

- Providing advice to management at all levels of the organization regarding decision making, action and communication;

- Conduct research, carry out, and evaluate programs and communication actions on a regular basis;

- Conduct planning and implementation of organizational efforts to influence or change public policies;

- Determine goals, plans, budgets, recruitment, and training, and manage the resources needed.

\subsection{Public Relations Tasks}

Broom and Smith (1979) conceptualize the tasks of individual public relations practitioners into the four roles of expert prescriber, problem solving facilitator, communication facilitator, and communication technician [11], details as follows:

First, public relations practitioners as expert advisors (expert prescriber), who identify communication problems between organizations and the public and look for solutions to problems. When a public relations practitioner takes a role in this position, he will be regarded as an authority in public relations and solutions. The task of the expert advisor is to define the problem, develop the program, and take full responsibility for its implementation [10].

Second is as a facilitator of the problem-solving process, which collaborates with others in the organization to identify and resolve problems. The problem-solving facilitator is part of the strategic planning team. Public relations practitioners involved in this process assist other managers in the management process in solving organizational problems [10].

Third is as a communication facilitator, who acts as a liaison between the organization and its public. They must be sensitive, be good listeners and become mediators of communication between the organization and its stakeholders. Communication facilitators maintain two-way communication and keep communication channels open. Public relations practitioners involved in this process act as sources of information and official contact agents between the organization and the public [10].

The fourth is as a communication technician, whose job is to focus on technical matters such as writing press releases, making media lists, and making leaflets, and not being involved in problem solving. Most public relations practitioners fall into this category as communication technicians. They are absent when management defines communication problems and looks for solutions, and sometimes do not fully know what objectives to be achieved [10]. 


\subsection{Industry 4.0}

Industry terminology 4.0 was first mentioned in 2011 in Germany as a proposal for the development of a new concept of German economic policy based on high-level technological strategies namely cyber-physical systems, Internet of things (IoT), and Internet of Services (IoS) [12]. The fourth period of the industrial revolution was marked by the process of automation and full digitalization, as well as the use of information and electronic technology in the personal environment [12]. Although the transformation of the internet in the digital industry is still in the process, artificial intelligence, big data and connectivity show a new round of digital revolution in industry 4.0 [12].

Schwab (2016) believes that we are at the beginning of the fourth industrial revolution, which is built on the digital revolution with mobile internet, smaller and stronger sensors that are cheaper and more affordable, and artificial intelligence and machine learning [13]. Industry 4.0's need is to convert regular machines into machines that can learn independently to improve the overall performance of maintenance and management with interactions around it [14].

\subsection{Artificial Intelligence}

"Artificial intelligence (AI) is a system that can think and act rationally like humans" [15]. "Artificial intelligence can learn from previous situations to provide input and automate complex decision making in the future, making it easier and faster to arrive at concrete conclusions based on data and past experience" [13]. The birth of artificial intelligence in 1956 was thanks to the role of John McCarthy along with Marvin Minsky, Claude Shannon, and Nathaniel Rochester at Dartmouth College. All four are recipients of Alan Turing's gift, a pioneer of the intelligent machinery concept that inspired the birth of artificial intelligence. Together they created a computer program that can think non-numerically which came to be known as 'artificial intelligence' [15].

In 1970 Minsky even predicted the future projections of artificial intelligence as follows: "in 3 to 8 years we will have machines with general intelligence of average humans, who can read Shakespeare, grease cars, play politics in the office, tell a joke, and have a fight. At that time, the machine will start educating itself with fantastic speed. "[16].

The definition of artificial intelligence used by McCarthy, Minsky, Shannon, and Rochester refers to the ability of machines to understand, think, and learn in a manner similar to humans, demonstrating the ability of computers to simulate human intelligence [15]. Since the 1970s, artificial intelligence has spread its wings to the field of research, including proof of mechanical theorems, machine translators, expert systems, game theory, pattern recognition, machine learning, robots, and control [17]. One part of artificial intelligence is machine learning, which is a machine that can improve its ability through experience [18]. Artificial intelligence has impacts on business and the economy such as production, communication, marketing and labor costs [19]. 


\section{Results and Discussion}

\subsection{PR practitioner's understanding on Artificial Intelligence}

Artificial intelligence in the context of public relations can be conceptualized as "technology that shows cognitive abilities and functions like humans in public relations activities, both independently and together with public relations practitioners" [20]. While PR practitioner's understanding on AI described as follows:

It could be software, machine or robot, I've seen once in Japan, a robot that could do customer service job. (AN)

Artificial intelligence can stick anywhere, it's like the brain, it can stick to robots, machines, or tools that can be programmed with AI. The point is that AI is automation, tasks that was previously done by humans can be automated with machines. (PW)

In my opinion, AI is software. AI is a computer program that can study problems and provide solutions to those problems. (RDM)

AI is not as sophisticated as we thought. AI is just programming. AI is just a marketing term, to make it sounds sophisticated. (SS)

\subsection{PR practitioners' perceptions towards AI capabilities on doing PR practices}

PR practitioner's thoughts on AI capabilities tend to be sceptical. They have doubts that AI capabilities would be the same as human PR practitioners. They said:

It's impossible to replace the real PR profession because it's not that easy ... PR work is so complex, so that's the AI must be very sophisticated first.. maybe in year 2100.. (AN)

AI can do things at the entry level tasks ... but it can't do complex work. (RDM)

For the moment it is unlikely to happen, but for the future it is possible for PR jobs that are replaceable by machine $(\mathrm{PW})$

Actually there are some tasks that can be replaced and some that are not. (SS)

Although it could be possible, it would require a very complicated computing (PDP)

Participants' doubts due to their consideration that:

$P R$ work requires a unique competence, right? There should be empathy, reasoning, emotion, and unlimited creativity, and it can't be possessed by artificial intelligence, at least for the time being. (AN)

Tasks that are need a face to face situation with humans can not be replaced by AI. (PW)

The more robots learns the more he can do many things. But he can't do things he doesn't learn. There, the superiority of humans is in terms of creativity, they can do things that are not determined by the program. (RDM)

AI can only do things that are predictable and patterned.. (PDP) 
Participants shared similar ideas that some nature of human being such as emotions and intuitions could not be achieved by AI. Also such intelligence has its own level, Huang and Rust (2018) developed a theory called AI Job Replacement Theory which divides four levels of intelligence to measure the extent to which AI will replace human work. The four levels of intelligence are: mechanical intelligence, analytical intelligence, intuitive intelligence, and empathy intelligence [8].

Mechanical intelligence require limited training or education [8]. Public relations tasks that can categorized into this type of intelligence are the distribution of press releases, making media lists, making transcripts from audio and video into text. Analytical intelligence require training and expertise on data and analysis, this intelligence is obtained from practice and expertise [8]. Applications of artificial intelligence at this level are machine learning and data analysis. Public relations tasks that can be categorized into this type of intelligence are social media monitoring and predicting media trends.

Intuitive intelligence is the ability to think creatively and adjust to novel times., it includes skills that require insights and creative problemsolving [8]. Examples of professions at this level of intelligence are public relations managers, or public relations practitioners who work as facilitators of the problem-solving process. Complex tasks and creativity require intuitive intelligence. While empathy intelligence require social, communication, and relationship building skills [8]. Included in this intelligence are leadership, advocacy and negotiation [8]. The task of public relations practitioners as public relations expert advisors or duties as communication facilitators are part of this intelligence.

In theory, artificial intelligence is very likely to be used to help humans completed a public relations task. Likewise in public relations practice, artificial intelligence technology has the opportunity to perform technical tasks such as: distributing press releases, making media lists, making transcripts of audio and video into text, predicting media trends, monitoring social media, furthermore, artificial intelligence technology is also predicted to be able to make recommendations what steps should be taken in a crisis situation in an organization [21].

Huang and Rust distinguish between jobs, tasks, and labor, as follows: work is a series of tasks done by workers; a task is a group that forms a job; and labor is a human being involved in joint production [8]. This theory asserts that for artificial intelligence to replace humans it is likely to occur fundamentally at the tasks level, not at the jobs level, starting with the task with the lowest and easiest intelligence level first. Participants mention some tasks that possibly has been achieved by AI and currently applied on PR works like media monitoring, data crawling and data mining, trend analysis, and interpreting data.

Social media analysis that can be done by artificial intelligence includes the activities of collecting, monitoring, analyzing, summarizing, and visualizing data obtained from social media that aims to facilitate online conversations and interactions and explore patterns that are useful for decision making in organizations [22]. Artificial intelligence is predicted to be able to do real-time analysis of shifting sentiments on social media so that it can identify the causes or contributors of certain problems and crises faced by organizations. Artificial intelligence will also make public relations practices more efficient and affordable, thereby increasing organizational profit [20].

Beiner (2019) created an application in the form of a web based on academic research by Frey and Osborne (2017) which created a directory of jobs that might be replaced by robots or artificial intelligence. The web provides search facilities for different types of work and the search results show what percentage of job automation is possible by artificial intelligence and 
its ranking, the higher the ranking, the less likely the job is to be replaced by artificial intelligence or robots. For the PR manager's job, the probability of automation is 1.5 percent and is ranked 67 out of 702 types of work. Thus, the work of a PR manager likely will never be replaced by artificial intelligence or robots. For the work of PR practitioners (Public Relations Officer) the automation is 18 percent and is ranked 201 out of 702 types of work. This means that the work of a PR practitioner will almost certainly not be replaced by artificial intelligence or robots [23][24].

\subsection{PR practitioners' anxiety towards AI disruptions}

Overall, participants has no fear or anxiety towards AI disruptions. Otherwise they perceived AI as tools that could help build their PR career. Participants' responds when asked whether they feel disrupted with presence of AI varies as follows:

AI will be very helpful.. will help us a lot in matter of monitoring the news to be more concise because this tasks takes a lot of time for workers to analyze trends one by one, with the help of AI maybe our work we used to do 3 hours might be done in just 5 minute, right? Now that makes it easier. No, I don't feel disturbed or disrupted. (AN)

I have no worries whatsoever, instead it (AI) will help me. So the human level will be higher than just doing technical work such as media monitoring, or news clipping, content automation, or delivering press release ... it will raise the level of PR work itself, so maybe the $P R$ practitioners who don't upgrade themselves will be disrupted. But those who have changed their mindset see the current situation and what they need to do to update their abilities, then they will survive and he will be leading this AI. (PW)

Humans must upgrade their analytic abilities and creativity. Because even though a robot can collect data and information that reads data and interprets information, it remains human who makes decisions where an institution must take action based on the data obtained

from the robot, so the robot is actually a human tool, isn't it? Not the one who takes the decision, but gives recommendations. But still the decision is in the hands of humans. (RDM)

Disrupted? Yes.. but in the future we should not assume AI as a scourge that can destroy PR job, but as PR we must develop strategies so that this AI becomes our friend in the end.

It should also be noted that artificial intelligence will only have serious social consequences when artificial intelligence reaches the level of High-Level Machine Intelligence (HLMI), which is a condition where artificial intelligence machines without human assistance can complete each task better and cheaper than human labor [2].

\section{Conclusions}

Artificial intelligence is still quite new to day-to-day public relations practices in Indonesia, some practitioners have begun to learn how to use it, like data crawling, media monitoring and interpreting data. Currently, utilization of artificial intelligence in public 
relations tasks is limited to monitoring and analysis of social media and activities on the internet that provide a picture of the pattern of human activity on social media and the internet, so that it can be a basis for decision making for public relations practitioners. AI is a tools that help carry out the tasks of public relations practitioners. It can be concluded that PR Practitioners think that the role of AI is limited to the level of communication technician. At the moment, the task of artificial intelligence is nothing more than collecting, processing and interpreting data. The artificial intelligence used in public relations practice has not yet reached the level of High-Level Machine Intelligence (HLMI), where the costs required to carry out public relations tasks by artificial intelligence are lower than if it done by humans.

Unlike the completion of tasks, the completion of public relations work is a complex matter. According to AI Job Replacement Theory, utilization of AI on PR works is at the level of mechanical intelligence and analytical intelligence. It's role is only as communication technician, the lowest level on PR role, and not at the managerial level that involves the ability to define and solve problems.

Emotional and cognitive components are important in artificial intelligence systems to make it more human where emotions play an important role in the process of human decision making, so emotions must be embedded in the process of reasoning when we try to model human reactions, especially when used to influence the behavior of others [25]. While artificial intelligence is scientific, public relations practice has elements of art and creativity in its implementation. Bringing up the elements of art, creativity, cognition and emotion in artificial intelligence will certainly require a tremendous effort. Thus, it can be concluded that the job of public relations practitioners will not be replaced by artificial intelligence, at least in the near future.

\section{Acknowldegement}

The author would like to thank to the Ministry of Research and Technology of the Republic of Indonesia, who has funded this research through the SAINTEK RISTEKDIKTI scholarship.

\section{References}

[1] D. Rotman, "How Technology Is Destroying Jobs," Technology Review, 2013.

[2] K. Grace, J. Salvatier, A. Dafoe, B. Zhang, and O. Evans, "Viewpoint: When will AI Exceed Human Performance? Evidence from AI Experts," J. Artif. Intell. Res., vol. 62, pp. 729-754, 2018.

[3] D. F. Glas, K. Wada, M. Shiomi, T. Kanda, H. Ishiguro, and N. Hagita, "Personal Greetings: Personalizing Robot Utterances Based on Novelty of Observed Behavior," Int. J. Soc. Robot., vol. 9, pp. 181-198, 2017.

[4] Republika, "Hasil Penelitian, Pekerjaan PR Ini akan Tergantikan Mesin," Republika Online, 2019. [Online]. Available: https://nasional.republika.co.id/berita/nasional/umum/pon8a0349/hasilpenelitian-pekerjaan-pr-ini-akan-tergantikan-mesin. [Accessed: 21-Mar-2019].

[5] W. Ekonomi, "Dear Para Pelaku PR, Siap untuk Hadapi Disrupsi AI dan Big Data?," Warta Ekonomi Online, 2019. [Online]. Available: https://www.wartaekonomi.co.id/read220103/dearpara-pelaku-pr-siap-untuk-hadapi-disrupsi-ai-dan-big-data.html?utm_source=dable. [Accessed: 21Mar-2019].

[6] E. N. Dewi, "Profesi Public Relations Akan Tergerus Artificial Intelligence," Pikiran Rakyat Online, 2019. [Online]. Available: https://www.pikiran-rakyat.com/bandung- 
raya/2019/02/17/profesi-public-relations-akan-tergerus-artificial-intelligence. [Accessed: 21-Mar2019].

[7] PERHUMAS, "Era Industri 4.0 - Apa Tantangan Hubungan Masyarakat Di Masa Depan?," PERHUMAS, 2018. [Online]. Available: http://www.perhumas.or.id/?p=4854. [Accessed: 21-Mar2019].

[8] M. H. Huang and R. T. Rust, “Artificial Intelligence in Service,” J. Serv. Res., vol. 21, no. 2, pp. 155-172, 2018.

[9] A. Theaker, The Public Relations Handbook, 2nd ed. Oxfordshire: Routledge, 2004.

[10] S. M. Cutlip, A. H. Center, and G. M. Broom, Effective Public Relations. Jakarta: Kencana, 2006.

[11] G. M. Broom and G. D. Smith, "Testing the practitioner's impact on clients," Public Relat. Rev., vol. 5 , no. 3, pp. 47-59, 1979.

[12] V. Roblek, M. Meško, and A. Krapež, "A Complex View of Industry 4.0," SAGE Open, vol. AprilJune, pp. 1-11, 2016.

[13] K. Schwab, The Fourth Industrial Revolution. New York: Crown Business, 2016.

[14] J. Lee, H. A. Kao, and S. Yang, "Service innovation and smart analytics for Industry 4.0 and big data environment," in Procedia CIRP, 2014, pp. 3-8.

[15] S. Russell and P. Norvig, Artificial Intelligence: A Modern Approach, 2nd ed. New Jersey: Pearson Education, 2003.

[16] J. L. King and J. Grudin, "Will Computers Put Us Out of Work?," Computer (Long. Beach. Calif)., vol. 49, no. 5, pp. 82-85, 2016.

[17] Y. Pan, "Heading toward Artificial Intelligence 2.0," Engineering, vol. 2, pp. 409-412, 2016.

[18] M. Tegmark, Life 3.0: Being human in the age of artificial intelligence. Knopf, 2017.

[19] C. Dirican, "The Impacts of Robotics, Artificial Intelligence On Business and Economics," Procedia - Soc. Behav. Sci., vol. 195, pp. 564-573, 2015.

[20] C. Galloway and L. Swiatek, "Public relations and artificial intelligence: It's not (just) about robots," Public Relat. Rev., vol. 44, no. 2018, pp. 734-740, 2018.

[21] W. Marx, "Artificial Intelligence and PR: What You Need to Know," Marx Communications, 2017. [Online]. Available: https://b2bprblog.marxcommunications.com/b2bpr/artificialintelligence-and-pr. [Accessed: 25-Mar-2019].

[22] D. Zeng, H. Chen, R. Lusch, and S. H. Li, "Social media analytics and intelligence," IEEE Intelligent Systems, 2010.

[23] C. B. Frey and M. A. Osborne, "The future of employment: How susceptible are jobs to computerisation?," Technol. Forecast. Soc. Change, vol. 114, pp. 254-280, 2017.

[24] F. Beiner, "Will Robots Take My Job? Will My Job Be Automated? · Replaced By Robots!?," Replaced by Robot, 2019. [Online]. Available: https://www.replacedbyrobot.info/. [Accessed: 26Mar-2019].

[25] J. Martínez-Miranda and A. Aldea, "Emotions in human and artificial intelligence," Comput. Human Behav., vol. 21, pp. 323-341, 2005. 